\title{
Fragment Ion
}

National Cancer Institute

\section{Source}

National Cancer Institute. Fragment Ion. NCI Thesaurus. Code C54173.

In mass spectrometry, a product ion resulting from the dissociation of a precursor ion. 